\title{
Neurobiology of Delusions in Alzheimer's Disease
}

\author{
Zahinoor Ismail • Minh-Quan Nguyen • \\ Corinne E. Fischer • Tom A. Schweizer • \\ Benoit H. Mulsant • David Mamo
}

Published online: 15 March 2011

(C) Springer Science+Business Media, LLC 2011

\begin{abstract}
Alzheimer's disease (AD) is associated with cognitive and functional impairment as well as neuropsychiatric sequelae, including psychotic symptoms such as delusions and hallucinations. Strong evidence supports the need to study delusions separate from hallucinations. Integrating the epidemiology, clinical correlates, and neuropathological and genetic literature for delusions in $\mathrm{AD}$ allows us to speculate on etiology and mechanisms. Plaque and tangle deposition in individuals with susceptible alleles of serotonergic, muscarinic, nicotinic, or Apos4 genes appears to result in disruption of cortical circuitry, culminating in delusions. While delusions in $\mathrm{AD}$ correspond to a phenotype distinct from AD without delusions, subtypes of delusions may also define further distinct clinical entities.
\end{abstract}

Z. Ismail $\cdot$ M.-Q. Nguyen • B. H. Mulsant • D. Mamo

Centre for Addiction and Mental Health,

Geriatric Mental Health Program, University of Toronto,

1001 Queen St W,

Toronto, Ontario M6J 1H4, Canada

C. E. Fischer · B. H. Mulsant • D. Mamo

Department of Psychiatry, University of Toronto,

Toronto, Ontario, Canada

\section{E. Fischer}

Mental Health Service/Keenan Research Centre of the Li Ka

Shing Knowledge Institute, St. Michael's Hospital,

University of Toronto,

Toronto, Ontario, Canada

\section{T. A. Schweizer}

Keenan Research Centre of the Li Ka Shing Knowledge Institute and the Division of Neurosurgery, St. Michael's Hospital,

University of Toronto,

Toronto, Ontario, Canada

\section{Z. Ismail $(\bowtie)$}

Department of Psychiatry, University of Calgary,

140329 St NW,

Calgary, Alberta T2N 2T9, Canada

e-mail: zahinoor@gmail.com
Persecutory delusions may occur earlier in the illness and have a more significant genetic component than misidentification delusions, which are associated with increased cognitive impairment and advanced dementia. Clearly distinguishing between these two syndromes is essential to making progress in the area of delusions in AD.

Keywords Alzheimer's · Dementia · Psychosis · Delusions · Persecutory delusions $\cdot$ Misidentifications $\cdot$ BPSD .

Neuropsychiatry $\cdot$ Neuropsychiatric symptoms $\cdot$ NPS .

Neuropathology · Genetics · Cognition · Paranoia ·

Suspiciousness · Confabulation

\section{Introduction}

Despite being considered a disorder of cognition, Alzheimer's disease (AD) is associated with many neuropsychiatric symptoms (NPS) of clinical significance. NPS, also called behavioral and psychological symptoms of dementia (BPSD), are present in up to $97 \%$ of people diagnosed with dementia, resulting in suffering, caregiver distress, and extensive resource utilization [1]. These noncognitive manifestations of dementia are the primary reason for transfer of patients with dementia from general hospitals to psychiatric hospitals, and for their institutionalization out of the community [2]. Of these NPS, psychosis is prominent and consists of hallucinations and delusions. Hallucinations are perceptions in the absence of a stimulus, whereas delusions are fixed false beliefs that are neither amenable to reason nor consistent with cultural beliefs. This review focuses on research reports in which delusions in $\mathrm{AD}(\mathrm{AD}+\mathrm{D})$ can be discussed separately from psychosis in $\mathrm{AD}(\mathrm{AD}+\mathrm{P})$ in general, or in which the discussion of $\mathrm{AD}+\mathrm{P}$ is instructive to the understanding of $\mathrm{AD}+\mathrm{D}$.

The index patient of Alois Alzheimer [3] suffered from paranoid delusions that were a prominent part of her illness. 
Delusions in $\mathrm{AD}$ disease may have varying content, including delusions of persecution, theft, infidelity, abandonment, or that the patient's deceased loved ones are still living, as well as misidentification syndromes (MIS) [4]. Misidentification delusions frequently seen in $\mathrm{AD}$ often represent true neuropsychiatric manifestations of neurodegeneration and include Capgras type (the feeling that someone known to the patient is replaced by an impostor), phantom boarder syndrome (the feeling that strangers are living in the patient's house), mirror sign (patient misidentification of his or her own image in a mirror), and TV sign (television images misidentified as real) [5]. Despite the longstanding recognition that delusions are part of $\mathrm{AD}$, our understanding of the pathophysiology and pharmacotherapy of delusions is still incomplete. The aim of this review is to reconcile the clinical presentation with the neurobiological underpinnings of $\mathrm{AD}+\mathrm{D}$ with a focus on neuropathology and genetics in order to better guide future investigation and treatment.

\section{Phenomenology}

Strict diagnostic criteria for $\mathrm{AD}+\mathrm{P}$, written in the $D S M-I V$ format, have been proposed by Jeste and Finkel [6] and include the presence of delusions or hallucinations (auditory or visual) in the context of clinically diagnosed AD. Psychotic symptoms must not predate the onset of the dementia so that a prior history of a primary psychotic disorder such as schizophrenia, schizoaffective disorder, delusional disorder, or mood disorder with psychotic features must be ruled out. Similarly, psychotic symptoms presenting in the context of delirium or resulting from a general medical illness or the use of drugs or other substances are excluded from this proposed diagnostic category. This construct has been validated by Schneider and colleagues [7] in a reanalysis of a risperidone clinical trial in which the Behavioral Pathology in Alzheimer's Disease rating scale was used to capture delusions (mostly persecutory type) and hallucinations (of all types) persisting over 2 to 4 weeks. Of the 625 patients enrolled in the original trial for behavioral issues, $75 \%$ met the criteria for $\mathrm{AD}+\mathrm{P}$. Thus, while overlapping with agitation or aggression, $\mathrm{AD}+\mathrm{P}$ was a discrete clinical entity with patient demographics differing from the demographics of nonpsychotic patients with AD (AD-P). However, the breakdown between delusions and hallucinations was not reported.

An alternative set of "Alzheimer-associated psychotic disorder" criteria using a syndromic approach to taxonomy has been suggested by Lyketsos and colleagues [8]. In this construct, discrete affective and psychotic syndromes of $\mathrm{AD}$ have been delineated [8] and validated [9]. In a consecutive series of 771 patients with probable $\mathrm{AD}$, delusions diagnosed with the Psychosis Dementia Scale within the previous 4 weeks were subclassified into paranoid/misidentification and expansive domains. Although $33 \%$ of patients had delusions, only $7 \%$ of them had hallucinations, most of whom also had delusions.

A contrasting approach to that of Lyketsos et al. [8] is used by Cook and colleagues [10]. They identified and classified $\mathrm{AD}+\mathrm{P}$ subtypes based on the presence of individual psychotic symptoms in isolation from other behavioral symptoms. In a cross-sectional study of 188 possible and probable $\mathrm{AD}$ patients, factor and cluster analysis of Behavioral Rating Scale items identified 2 separate factors: a misidentification/hallucination factor (including symptoms of simple and delusional misidentifications and hallucinations) and a persecutory delusion factor. Subsequent analysis by the same group has demonstrated that impairment in verbal fluency and visuospatial function is restricted to the misidentification/ hallucination subtype, that the paranoid subtype does not differ from nonpsychotic $\mathrm{AD}$ patients on cognitive measures, and the ability to detect meaningful biologic associations of $\mathrm{AD}+\mathrm{P}$ would be enhanced by separate analyses of the misidentification and paranoid delusional phenotypes [11]. These results were consistent with the study of Forstl and colleagues [12] that found that delusions of misidentification were associated with greater cognitive impairment than the absence of delusions in a sample of patients with moderate to severe AD.

\section{Epidemiology and Risk Factors}

The results of epidemiologic studies of psychosis in dementia have been variable given the heterogeneity of the study group. A systematic review by Ropacki and Jeste [13] reported that $41 \%$ of patients with $\mathrm{AD}$ experience psychosis, including $23 \%$ with delusions, $5 \%$ with hallucinations, and $13 \%$ with both. The most common type of delusion is delusion of theft. In this review, AD+P was associated with a more rapid cognitive decline, and its incidence increased progressively over the first 3 years of the illness, with a subsequent plateau. Inadvertent inclusion of patients with Lewy body dementia and poor recollection of family history is considered a confound in these epidemiologic studies (as is the common failure to separate delusions from hallucinations). A more recent study conducted by Weamer and colleagues [14] assessed 361 patients diagnosed with possible or probable $\mathrm{AD}$ or mild cognitive impairment without psychosis at baseline. Patients were observed longitudinally until study completion, loss to follow-up, or until the patient became too impaired to return to the clinic for reassessment. Neurological evaluation, cognitive testing with the Mini-Mental State 
Examination (MMSE), and diagnostic re-evaluation (including assessment for the presence of psychosis) were conducted on an annual basis. $\mathrm{AD}+\mathrm{P}$ was observed in 122 (34\%) patients during the follow-up period. Global cognitive impairment (ie, the MMSE score) was the only baseline variable consistently associated with a reduced time to onset of psychosis, especially in those with early- to mid-stage disease. Unfortunately, despite a useful longitudinal approach, psychosis was not described in terms of its components, limiting the utility of this study in contributing to the understanding of the neurobiology of delusions. Very recently, in a cross-sectional sample of much older adults with $\mathrm{AD}$ (>85 years of age), Ostling and colleagues [15] reported that $22 \%$ had delusions and $30 \%$ had hallucinations. Although psychosis in general and hallucinations increased with dementia severity, no statistically significant association was found between delusions and dementia severity. This highlights the importance of separating delusions and hallucinations when studying the evolution of these symptoms in $\mathrm{AD}$.

The Cache County Dementia Prevalence study determined prevalence of NPS over a mean and median 5-year follow-up period after diagnosis in a sample with a mean duration of dementia of 2 years at baseline [1]. Point prevalence for delusions was $18 \%$ at baseline and $34 \%$ to $38 \%$ during the past three yearly visits; for hallucinations, it was $10 \%$ at baseline and $19 \%$ to $24 \%$ thereafter. Period prevalence over the 5 -year follow-up period was $60 \%$ for delusions and $38 \%$ for hallucinations. Gauthier and colleagues [16] reviewed the frequency of NPS in samples assessed with the Neuropsychiatric Inventory in three European studies: the Maastricht Study of Behavior in Dementia; the Réseaux Alzheimer Français; and the European Alzheimer Disease Consortium. Delusions occurred in $22 \%$ and hallucinations in $9 \%$ of these community samples. Sweet and colleagues [17] assessed the types of delusions present in individuals involved in the National Institute of Aging Late Onset AD Family Study. Among 478 unique participants having completed at least 1 behavioral assessment, psychotic symptoms were present in 239 (50\%). The most common psychotic symptoms were delusional misidentification of people $(23 \%)$, paranoia $(21 \%)$, and believing that dead people were still alive (19\%).

A large study by Harciarek and Kertesz [18] investigated the prevalence of MIS in 392 individuals with probable AD determined by a semistructured interview of patients and reliable caregivers. MIS were identified in $16 \%$ of participants. The most frequent form of MIS were Capgras delusions, often accompanied by reduplication of place, phantom boarder phenomenon, or both. As part of the Medical Research Council Cognitive Function and Aging study, Savva and colleagues [19॰] determined the prevalence and correlates of NPS in a cohort of 587 participants with dementia, and assessed subtypes of $\mathrm{AD}+\mathrm{D}$. At baseline, persecutory beliefs were held by $25 \%$ of individuals and misidentifications by $20 \%$. At 2 -year follow-up, the incidence of new misidentifications was higher than that of new persecutory delusions. A factor analysis revealed a four-factor solution, with persecutory delusions and misidentifications best fit on separate factors, again supporting the idea that these two types of delusions are separate phenomena with separate trajectories and possibly separate neurobiological underpinnings.

It can be difficult to differentiate between a true delusion and a belief that is secondary to other cognitive difficulties (eg, misplacing personal belongings and concluding that the items were stolen, or confabulating a story to make sense of one's confusing experience). This is particularly the case given that severity of cognitive dysfunction has been shown to be a strong predictor of $\mathrm{AD}+\mathrm{P}[14,20]$. However, in the descriptive analysis of the randomized VISTA (Video-Imaging Synthesis of Treating Alzheimer's Disease) trial [21], misplacements were distinguished from delusions, with $51 \%$ of patients with $\mathrm{AD}$ and misplacements not having delusions. In the $49 \%$ of patients with $\mathrm{AD}$ and misplacements who had delusions, $36 \%$ were delusions of theft. A recent Japanese study assessed the prevalence and risk factors for delusions of theft in a sample of $56 \mathrm{AD}$ patients: $25 \%$ of patients had delusions of theft, and these were associated with female gender, absence of cohabiting family members, neurotic personality, and retained social cognitive function [22].

Frontal impairment as measured by the Frontal Assessment Battery (FAB) has been associated with $\mathrm{AD}+\mathrm{D}$ in general and persecutory delusions in particular. Nagata and colleagues $[23 \cdot \bullet$ ] examined the relationship between persecutory delusions and frontal lobe function using the Japanese version of the FAB. A total of 48 probable $\mathrm{AD}$ patients (MMSE $\geq 18$ and Clinical Dementia Rating of 0.5 or 1.0) were divided into two groups: $\mathrm{AD}+\mathrm{D}$ and $\mathrm{AD}$ without delusions (AD-D). The groups did not differ significantly with regard to sex, age, duration of illness, education, or MMSE scores. However, mean (+SD) FAB scores were significantly different between the two groups $(\mathrm{AD}+\mathrm{D}, 11.6+2.8 ; \mathrm{AD}-\mathrm{D}, 13.9+2.5)$. Logistic regression showed that the FAB scores, but not the MMSE scores, were associated with persecutory delusions. In contrast, frontal executive functioning was not associated with confabulations in a sample of 22 probable AD patients with confabulation compared with 22 matched controls [24]. These findings implicate frontal lobe impairment specifically, and separately from global cognitive impairment in the presence of persecutory $\mathrm{AD}+\mathrm{D}$ (and not confabulation), and emphasize the need to evaluate cognition more closely in determining the association between cognition and delusional subtypes. 
Delusions also have been shown to have an impact on real world functioning in AD. A recent review by Fischer and colleagues [25] showed that delusions are associated with reduced functional performance in patients with $\mathrm{AD}$. The authors commented that studies conducted to date likely have underestimated the impact of delusions on daily functioning. This is due to an overreliance on functional assessment scales of basic versus instrumental activities of daily living, the use of crude assessments of cognition, and the lack of longitudinal assessments.

\section{Neuropathology}

Several postmortem and imaging studies have attempted to elucidate the neuropathology and neurochemistry of delusions in dementia. Using 27 autopsy-confirmed AD cases, Zubenko and colleagues [26] found that psychosis was associated with a significantly increased density of senile plaques and neurofibrillary tangles in the prosubiculum and middle frontal cortex, and found trends toward increases in the superior temporal and entorhinal cortices. Psychosis was also associated with the relative preservation of norepinephrine in the substantia nigra and a significant reduction in serotonin in the prosubiculum, with trends toward serotonin reduction in the middle frontal gyrus, superior temporal cortex, entorhinal cortex, substantia nigra, thalamus, amygdala, and caudate nucleus. Psychosis was not divided into delusions and hallucinations, limiting the interpretation of these data specifically for delusions.

Subsequently, Förstl and colleagues [27] investigated 56 patients with definite $\mathrm{AD}$ and focused on delusional subtypes. Misidentifications were associated with lower neuron counts in the area CA1 of the hippocampus, while paranoid delusions were observed in patients with less severe cell loss in the parahippocampal gyrus but with lower cell counts in the serotonergic dorsal raphe nucleus. MukaetovaLadinska and colleagues [28] reported that a positive history of misidentification delusions is related to an increased density of neuritic plaques in fronto-parieto-occipital lobes. Farber and colleagues [29] observed 109 patients with AD and after their death compared the pathology in those with and without psychosis. Delusions occurred in almost all patients with psychosis (94\%), and hallucinations in the absence of delusions were very rare (6\%). Suspiciousness was the most common delusion, present in $62 \%$, with misidentifications present in $43 \%$. Although there were no differences in total senile plaques or cored senile plaques, a greater density of neocortical neurofibrillary tangles was found in $\mathrm{AD}+\mathrm{D}$ as compared with $\mathrm{AD}-\mathrm{D}$. This increase was independent of dementia severity.

Lai and colleagues [30] used postmortem radioligand binding assays to quantify muscarinic receptors in $\mathrm{AD}$ patients. Overall, there was a decrease in $\mathrm{M}_{2}$ density in the frontal lobes of patients with $\mathrm{AD}$ compared with controls. Within the group of AD patients, $\mathrm{M}_{2}$ receptor density was higher in Brodmann area 11 (orbitofrontal cortex) of the patients with delusions than in those without delusions. A postmortem magnetic resonance spectroscopy study identified markers suggesting greater neuropil disruption in the dorsolateral prefrontal cortex, superior temporal gyrus, and inferior parietal cortex in $\mathrm{AD}+\mathrm{P}$ compared with $\mathrm{AD}-\mathrm{P}$ patients [31]. One can speculate that this greater disruption represents an acceleration of $\mathrm{AD}$-related neurodegeneration. Proton magnetic resonance spectroscopy also allows the indirect measurement of $\mathrm{AD}$ pathology in living patients and has been used to implicate the anterior cingulate cortex (ACC) in patients with mild $\mathrm{AD}$ and delusions compared with those without delusions [32]. Delusional thinking was assessed in $30 \mathrm{AD}$ patients using the BEHAVE-AD (Behavioral Pathology in Alzheimer's Disease) scale, and compared with AD-D patients $(n=22), \mathrm{AD}+\mathrm{D}$ patients $(n=8)$ had significantly decreased $\mathrm{N}$-acetylaspartate/creatine ratio (a marker of neuronal density, decreased in AD) and increased myo-inositol/creatine ratio (an early marker of AD) in the ACC. Of importance in this study was the finding that these markers were unrelated to cognition, thus implicating early and distinct neuropathology in the ACC in the development of psychosis. The distribution of persecutory and misidentification delusions was not reported.

\section{Genetics}

Although there is clear evidence for the heritability of $\mathrm{AD}+\mathrm{P}$ [17], there is also evidence that $\mathrm{AD}+\mathrm{D}$ specifically is a heritable trait. Familial aggregation studies of probands and siblings with $\mathrm{AD}$ have shown a higher chance of concordance for $\mathrm{AD}+\mathrm{D}$ in siblings and probands than by chance alone [33]. Using genome scans of 148 AD pedigrees, Avramopoulos and colleagues [34] identified a locus on chromosome $2 \mathrm{p}$ that is linked with $\mathrm{AD}+\mathrm{D}$ and a locus on $14 \mathrm{q}$ that predisposes individuals to a form of dementia without comorbid psychotic features.

The role of ApolipoproteinE $\varepsilon 4$ (Apo\&4) in $\mathrm{AD}+\mathrm{P}$ is unclear due to conflicting studies using varying methodologies [35]. When addressing delusions specifically, there is evidence supporting the role of Apos 4 in predicting $\mathrm{AD}+\mathrm{D}$. In a study of 158 patients with $\mathrm{AD}$, delusions correlated with number of Apos4 alleles [36]. In a prospective study of 87 patients with $\mathrm{AD}$, the number of Apos4 alleles was predictive of delusions, with 1 allele carrying a 2.5 -fold risk and 2 alleles a 5.6-fold risk [37]. In another longitudinal study of $151 \mathrm{AD}$ patients of all severities observed in a memory clinic, the presence of at least one Apos 4 allele conferred increased hazard ratios for the development of 
delusions (3.4-fold) and hallucinations (19.0-fold) [38]. In a sample of 171 patients with late-onset $\mathrm{AD}$ consecutively admitted to a memory clinic, the presence of at least one Apos4 allele significantly increased the risk of developing delusions in the early stage of the illness compared with the absence of this allele. This association did not hold for hallucinations or psychosis in general [39]. In a study looking at $110 \mathrm{AD}$ patients, the number of Apos4 alleles has been associated with prevalence and severity of delusions in $\mathrm{AD}$, with homozygosity conferring the greatest delusional burden [40]. In a large independent cohort of 388 patients with longitudinal measures of NPS, the $\varepsilon 3 / \varepsilon 3$ genotype of the ApolipoproteinE gene was negatively associated with hallucinations but not significant for delusions, suggesting different genetic determinants for these separate phenomena [41]. In future studies of $\mathrm{AD}+\mathrm{D}$, Apo 4 status, age at onset of illness, and subtype of delusions will be important factors in characterizing the sample group.

Genes involved in neurotransmitter systems have been identified as important in the pathogenesis of $\mathrm{AD}+\mathrm{D}$. There is mixed evidence for the serotonin $2 \mathrm{~A}(5 H T-2 A)$ receptor single nucleotide polymorphism $102 \mathrm{~T} / \mathrm{C}$. Association studies have identified the $\mathrm{T}$ allele as the risk allele for $\mathrm{AD}+\mathrm{D}$ [42]. The $\mathrm{T}$ allele also has been associated with a higher prevalence of delusions and treatment resistance to second-generation antipsychotics [43]. The $\mathrm{C}$ allele has been found to be protective for delusions [44] but to be the risk allele for hallucinations in the absence of delusions [45]. Similarly, with the 5HT-2C single nucleotide polymorphism Cys23Ser, Ser 23 was found to be the risk allele for hallucinations in the absence of delusions, and this effect was additive to 5HT-2A C102 [45]. The serotonin transporter promoter region $(5 H T-T P R)$ also has been implicated in $\mathrm{AD}+\mathrm{D}$. Homozygosity for the long arm leads to an increase in 5HTT mRNA transcription and $5 H T$ uptake compared with genes containing at least one short arm and is protective for $\mathrm{AD}+\mathrm{D}$ [46]. The dopaminergic system also has been investigated, with dopamine receptor DRD3 1/1 allele implicated in delusions compared with the DRD3 2/2 allele [47]. However, much more work is required to help us better understand the role of neurotransmitter genetics in $\mathrm{AD}+\mathrm{D}$.

The idea that so-called psychosis-modifier genes may act similarly during neurodevelopment to produce schizophrenia, or throughout neurodegeneration to produce $\mathrm{AD}+\mathrm{P}$ was supported by an investigation of the interleukin (IL)-1 $\beta$ gene [48]. Functional $I L-1 \beta$ promoter polymorphisms have been associated with $\mathrm{AD}+\mathrm{D}$, leading to speculation that diminished $I L-1 \beta$ output may promote the psychotic phenotype through altered neurotransmitter interaction (via $D A$ or $5 H T$ ) or reduced neuronal repair after amyloidmediated neurotoxicity. Carson and colleagues [49•] have investigated genetic variations in the $\alpha 7$ nicotinic receptor and psychotic symptoms in AD. Sampling 409 individuals from the Northern Ireland BPSD cohort, an association was found between the rs6494223 $\mathrm{T}$ allele and delusional symptoms in $\mathrm{AD}$. The frequency of delusional symptoms was higher in patients homozygous for the $\mathrm{T}$ allele compared with the CC or CT genotypes. This result was not confounded by MMSE scores. Also of interest was the location of the single nucleotide polymorphism close to D15S1360, the dinucleotide repeat polymorphism associated with schizophrenia. Table 1 summarizes the neuropathological and genetics findings associated with $\mathrm{AD}+\mathrm{D}$. Table 2 reviews the differences between misidentification and persecutory delusions in $\mathrm{AD}$.

\section{Discussion}

The study of $\mathrm{AD}+\mathrm{D}$ is an evolving field that is becoming more refined with time. Historically, $A D+D$ was almost exclusively discussed within the context of $\mathrm{AD}+\mathrm{P}$, but more literature assessing delusions as separate from hallucinations and assessing subtypes of delusions is emerging. Understanding the presentation, epidemiology, association with cognitive impairment in specific domains, and rate of cognitive decline of persecutory versus misidentification delusions is essential in understanding the neurobiological underpinnings of these syndromes. The absence of controlling for the confounding factors limits the interpretation of much of the existing literature.

Neuropathological studies emphasize the important roles of plaque and tangle density in $\mathrm{AD}+\mathrm{D}$, suggesting that frontal plaques and tangles are associated with delusions. The effect of these plaques and tangles on neurotransmitter systems may underscore their role in manifestation of the illness. Serotonergic systems are disrupted in psychosis both cortically and subcortically and are associated with persecutory delusions rather than misidentifications. Muscarinic density in the orbitofrontal cortex also has been linked to AD+D. Furthermore, cortical cell loss is associated with persecutory delusions, whereas hippocampal cell loss (and thus cognitive impairment) is associated with misidentifications. The triaxial inclusion of plaque and tangle density, plaque and tangle location, and effect on neurotransmitter systems results in a complicated neuropathological model of $\mathrm{AD}+\mathrm{D}$. Difficulty in controlling for the various permutations and combinations of these three variables underscores the heterogeneity of data in this area. Further neuropathological studies with clearly described clinical samples are warranted.

Genetic studies to date have established strong heritability for psychosis in AD, suggesting a role for Apos4 load in delusional thinking, providing potential links to genes associated with primary psychotic disorders, and starting to identify potential neurotransmitter targets for pharmacologic 
Table 1 Summary of neuropathology, genetics, and cognition for Alzheimer's disease with delusions

\begin{tabular}{|c|c|c|c|}
\hline & Neuropathology & Genetics & Cognition and function \\
\hline $\begin{array}{l}\text { Alzheimer's } \\
\text { disease } \\
\text { with } \\
\text { delusions }\end{array}$ & $\begin{array}{l}\text { Greater density of neocortical neurofibrillary } \\
\text { tangles in } \mathrm{AD}+\mathrm{D} \text { compared with } \mathrm{AD}-\mathrm{D} \\
\text { Higher muscarinic receptor }\left(\mathrm{M}_{2}\right) \text { density in the } \\
\text { orbitofrontal cortex (Brodmann area } 11) \text { in } \\
\mathrm{AD}+\mathrm{D} \text { compared with } \mathrm{AD}-\mathrm{D} \\
\text { Significantly decreased } \mathrm{N} \text {-acetylaspartate/cre- } \\
\text { atine ratio and increased myo-inositol/crea- } \\
\text { tine ratio in the anterior cingulate cortex in } \\
\mathrm{AD}+\mathrm{D} \text { compared with AD-D }\end{array}$ & 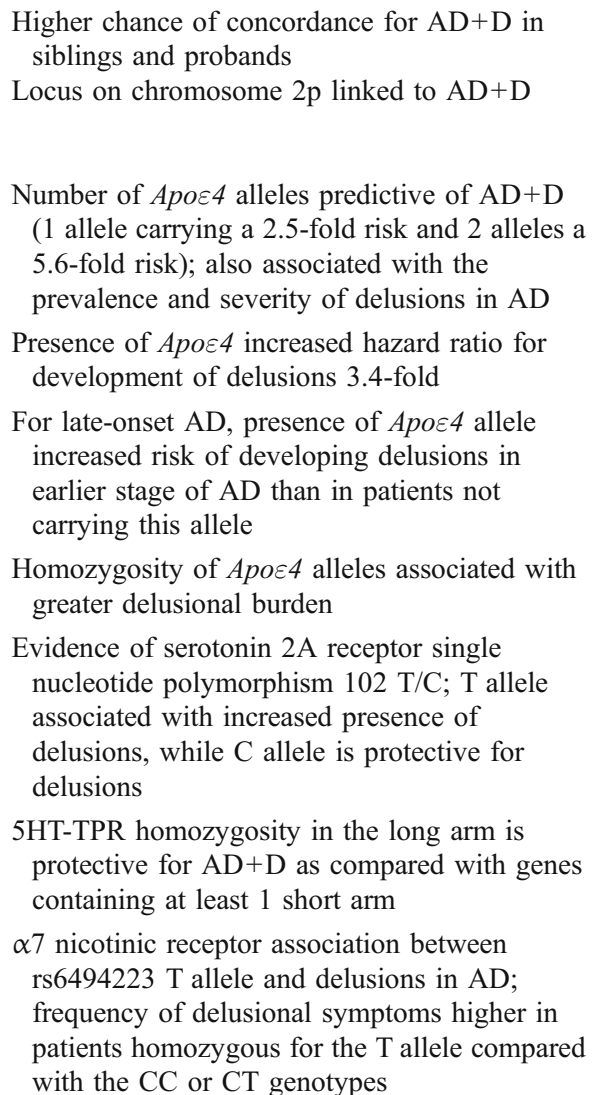 & $\begin{array}{l}\text { Delusions may be } \\
\text { associated with worse } \\
\text { functional performance } \\
\text { in AD patients }\end{array}$ \\
\hline
\end{tabular}

5HT-TPR serotonin transporter promoter region, $A D$ Alzheimer's disease, $A D+D$ Alzheimer's disease with delusions, $A D-D$ Alzheimer's disease without delusions

intervention. A recent clinical trial demonstrated the efficacy of citalopram in treating the psychosis of dementia, further implicating serotonergic mechanisms [50].

Relating the neuropathological and genetic findings using structural and functional imaging studies holds promise for the identification of endophenotypes that can then be used in future mechanistic and pharmacologic studies. Ideally, these future studies will control for the many variables in the clinical sample. Practically, however, this is difficult. To further investigate delusions in dementia, several steps must be taken. This starts with uniformity in diagnosis. A uniform standard of qualifying and quantifying $\mathrm{AD}+\mathrm{D}$ is essential.

Table 2 Differences between misidentification and persecutory delusions in Alzheimer's disease

\begin{tabular}{|c|c|c|}
\hline & Neuropathology & Cognition and function \\
\hline \multirow[t]{2}{*}{$\begin{array}{l}\text { Misidentification } \\
\text { delusions }\end{array}$} & $\begin{array}{l}\text { Lower neuron counts in the area CA1 of } \\
\text { the hippocampus }\end{array}$ & Greater cognitive impairment at baseline vs AD-D \\
\hline & $\begin{array}{l}\text { Increased density of neuritic plaques in the } \\
\text { fronto-parieto-occipital lobes }\end{array}$ & $\begin{array}{l}\mathrm{AD}+\mathrm{D} \text { patients with hallucinations show greater impairment in verbal fluency } \\
\text { and visuospatial function compared with } \mathrm{AD}-\mathrm{D} \text { patients }\end{array}$ \\
\hline \multirow[t]{2}{*}{$\begin{array}{l}\text { Persecutory } \\
\text { delusions }\end{array}$} & $\begin{array}{l}\text { Associated with cortical and subcortical } \\
\text { serotonergic system disruption }\end{array}$ & $\begin{array}{l}\text { Greater frontal impairment measured by the Frontal Assessment Battery (AD } \\
\quad+\mathrm{D}, 11.6 \pm 2.8 \text {; AD-D } 13.9 \pm 2.5)\end{array}$ \\
\hline & $\begin{array}{l}\text { Less severe cell loss in the } \\
\text { parahippocampal gyrus } \\
\text { Lower cell counts in the serotonergic } \\
\text { dorsal raphe nucleus }\end{array}$ & $\begin{array}{l}\text { Frontal Assessment Battery scores significantly influenced by the } \\
\text { manifestation of persecutory delusions }\end{array}$ \\
\hline
\end{tabular}

$A D+D$ Alzheimer's disease with delusions, $A D-D$ Alzheimer's disease without delusions 
This standard should be valid and reliable and should specifically characterize the dementia and the delusional subtypes. Stage and age at onset of dementia are crucial, as is the duration of delusional thinking. Future studies should accurately report as much demographic and clinical data as possible in order to make comparisons of the literature more valid and further elucidate the etiopathology of $\mathrm{AD}+\mathrm{D}$.

\section{Conclusions}

Integrating the epidemiology, clinical correlates, and the neuropathological and genetic literature in $\mathrm{AD}+\mathrm{D}$ allows us to speculate on the etiology and mechanisms of $\mathrm{AD}+\mathrm{D}$. Plaque and tangle deposition in genetically predisposed individuals with susceptible alleles of serotonergic, muscarinic, nicotinic, or Apos4 genes appears to result in disruption of cortical circuitry, culminating in delusions in the context of $\mathrm{AD}$. Although delusions in $\mathrm{AD}$ seem to correspond to a phenotype distinct from AD-D, subtypes of delusions may also define further distinct clinical entities. Persecutory delusions may occur earlier in the illness and have a more significant genetic component than misidentification delusions, which are associated with increased cognitive impairment and advanced dementia. Clearly distinguishing between these two syndromes is essential for making progress in the area of $\mathrm{AD}+\mathrm{D}$.

Acknowledgments Dr. Mulsant has served on boards for the Center for Addiction and Mental Health (CAMH) and the CAMH Foundation and has received grant support from the National Institutes of Health and the Canadian Institutes of Health Research.

Dr. Mamo has received grant support from the National Institute of Mental Health and the Canadian Institute of Health Research.

Disclosure Dr. Mulsant has received donations of medication for use in National Institutes of Health-funded clinical trials from BristolMyers Squibb, Pfizer, and Wyeth and previously held stock in AkzoNobel, Alkermes, AstraZeneca, Biogen Idec, Celsion Corp., Elan Corp., Eli Lilly and Company, Forest Laboratories, Orchestra Therapeutics, and Pfizer.

Dr. Mamo has received grant support from Pfizer.

Drs. Ismail, Fischer, and Schweizer, and Minh-Quan Nguyen reported no potential conflicts of interest relevant to this article.

\section{References}

Papers of particular interest, published recently, have been highlighted as:

- Of importance

•. Of major importance

1. Steinberg M, Shao H, Zandi P, et al. Point and 5-year period prevalence of neuropsychiatric symptoms in dementia: the Cache County Study. Int J Geriatr Psychiatry. 2008;23:170-7.
2. Wiener PK, Kiosses DN, Klimstra S, et al. A short-term inpatient program for agitated demented nursing home residents. Int $\mathrm{J}$ Geriatr Psychiatry. 2001;16:866-72.

3. Alzheimer A. Uber eine eigenartige rkrankung der hirnrinde. Allg Z Psychiat Psych Gerichtl Med. 1907;64:146-8.

4. Fischer C, Bozanovic-Sosic R, Norris M. Review of delusions in dementia. Am J Alzheimer's Dis Other Dements. 2004;19:19-23.

5. Holt AE, Albert ML. Cognitive neuroscience of delusions in aging. Neuropsychiatr Dis Treat. 2006;2:181-9.

6. Jeste DV, Finkel SI. Psychosis of Alzheimer's disease and related dementias. Diagnostic criteria for a distinct syndrome. Am J Geriatr Psychiatry. 2000;8:29-34.

7. Schneider LS, Katz IR, Park S, et al. Psychosis of Alzheimer disease: validity of the construct and response to risperidone. Am J Geriatr Psychiatry. 2003;11:414-25.

8. Lyketsos CG, Breitner JC, Rabins PV. An evidence-based proposal for the classification of neuropsychiatric disturbance in Alzheimer's disease. Int J Geriatr Psychiatry. 2001;16:1037-42.

9. Mizrahi R, Starkstein SE, Jorge R, et al. Phenomenology and clinical correlates of delusions in Alzheimer disease. Am J Geriatr Psychiatry. 2006;14:573-81.

10. Cook SE, Miyahara S, Bacanu SA, et al. Psychotic symptoms in Alzheimer disease: evidence for subtypes. Am J Geriatr Psychiatry. 2003;11:406-13.

11. Perez-Madrinan G, Cook SE, Saxton JA, et al. Alzheimer disease with psychosis: excess cognitive impairment is restricted to the misidentification subtype. Am J Geriatr Psychiatry. 2004;12:449-56.

12. Forstl H, Besthorn C, Burns A, et al. Delusional misidentification in Alzheimer's disease: a summary of clinical and biological aspects. Psychopathology. 1994;27:194-9.

13. Ropacki SA, Jeste DV. Epidemiology of and risk factors for psychosis of Alzheimer's disease: a review of 55 studies published from 1990 to 2003. Am J Psychiatry. 2005;162:2022-30.

14. Weamer EA, Emanuel JE, Varon D, et al. The relationship of excess cognitive impairment in MCI and early Alzheimer's disease to the subsequent emergence of psychosis. Int psychogeriatrics IPA. 2009;21:78-85.

15. Ostling S, Gustafson D, Blennow K, et al: Psychotic Symptoms in a Population- Based Sample of 85-Year-Old Individuals With Dementia. J Geriatr Psychiatry Neurol.

16. Gauthier S, Cummings J, Ballard C, et al. Management of behavioral problems in Alzheimer's disease. Int psychogeriatrics IPA. 2010;22:346-72.

17. Sweet RA, Bennett DA, Graff-Radford NR, et al. Assessment and familial aggregation of psychosis in Alzheimer's disease from the National Institute on Aging Late Onset Alzheimer's Disease Family Study. Brain. 2010;133:1155-62.

18. Harciarek M, Kertesz A. The prevalence of misidentification syndromes in neurodegenerative diseases. Alzheimer disease and associated disorders 2008; 22:163-169

19. - Savva GM, Zaccai J, Matthews FE, et al. Prevalence, correlates and course of behavioural and psychological symptoms of dementia in the population. Br J Psychiatry. 2009;194:212-9. This was a large longitudinal study that assessed the prevalence and incidence of NPS in dementia. Importantly, misidentifications were assessed separately from persecutory delusions and had differing incidence rates as well as differing associations in factor analysis.

20. Jeste DV, Wragg RE, Salmon DP, et al. Cognitive deficits of patients with Alzheimer's disease with and without delusions. Am J Psychiatry. 1992;149:184-9.

21. Hamilton L, Fay S, Rockwood K. Misplacing objects in mild to moderate Alzheimer's disease: a descriptive analysis from the VISTA clinical trial. J Neurol Neurosurg Psychiatry. 2009;80:960-5.

22. Murayama N, Iseki E, Endo T, et al. Risk factors for delusion of theft in patients with Alzheimer's disease showing mild dementia in Japan. Aging Ment Health. 2009;13:563-8. 
23. •• Nagata T, Ishii K, Ito T, et al. Correlation between a reduction in Frontal Assessment Battery scores and delusional thoughts in patients with Alzheimer's disease. Psychiatry Clin Neurosci. 2009;63:449-54. This was a very important study of the role of cognition and delusions in AD. Methodologically, this study is important because it assessed persecutory delusions as separate from misidentifications and used the FAB rather than a crude global measure such as the MMSE.

24. Nedjam Z, Devouche E, Dalla Barba G. Confabulation, but not executive dysfunction discriminate $\mathrm{AD}$ from frontotemporal dementia. Eur J Neurol. 2004;11:728-33.

25. Fischer CE, Verhoeff NP, Churchill K, et al. Functional outcome in delusional Alzheimer disease patients. A systematic review. Dement Geriatr Cogn Disord. 2009;27:105-10.

26. Zubenko GS, Moossy J, Martinez AJ, et al. Neuropathologic and neurochemical correlates of psychosis in primary dementia. Arch Neurol. 1991;48:619-24.

27. Forstl H, Burns A, Levy R, et al. Neuropathological correlates of psychotic phenomena in confirmed Alzheimer's disease. Br J Psychiatry. 1994;165:53-9.

28. Mukaetova-Ladinska EB, Harrington CR, Roth M, et al. Biochemical, neuropathological, and clinical correlations of neurofibrillary degeneration in Alzheimer's disease. In: Bergener M, Finkel SI, editors. Treating Alzheimer's and other dementias. New York: Springer; 1995. p. 57-80.

29. Farber NB, Rubin EH, Newcomer JW, et al. Increased neocortical neurofibrillary tangle density in subjects with Alzheimer disease and psychosis. Arch Gen Psychiatry. 2000;57:1165-73.

30. Lai MK, Lai OF, Keene J, et al. Psychosis of Alzheimer's disease is associated with elevated muscarinic M2 binding in the cortex. Neurology. 2001;57:805-11.

31. Sweet RA, Panchalingam K, Pettegrew JW, et al. Psychosis in Alzheimer disease: postmortem magnetic resonance spectroscopy evidence of excess neuronal and membrane phospholipid pathology. Neurobiol Aging. 2002;23:547-53.

32. Shinno $H$, Inagaki $T$, Miyaoka $T$, et al. A decrease in $\mathrm{N}-$ acetylaspartate and an increase in myoinositol in the anterior cingulate gyrus are associated with behavioral and psychological symptoms in Alzheimer's disease. J Neurol Sci. 2007;260:132-8.

33. Tunstall N, Owen MJ, Williams J, et al. Familial influence on variation in age of onset and behavioural phenotype in Alzheimer's disease. Br J Psychiatry. 2000;176:156-9.

34. Avramopoulos D, Fallin MD, Bassett SS. Linkage to chromosome 14q in Alzheimer's disease (AD) patients without psychotic symptoms. Am J Med Genet B Neuropsychiatr Genet. 2005;132:9-13.

35. DeMichele-Sweet MA, Sweet RA. Genetics of psychosis in Alzheimer's disease: a review. J Alzheimers Dis. 2010;19:761-80.

36. Weiner MF, Vega G, Risser RC, et al. Apolipoprotein E epsilon 4, other risk factors, and course of Alzheimer's disease. Biol Psychiatry. 1999;45:633-8.
37. Scarmeas N, Brandt J, Albert M, et al. Association between the APOE genotype and psychopathologic symptoms in Alzheimer's disease. Neurology. 2002;58:1182-8.

38. Chang JB, Wang PN, Chen WT, et al. ApoE epsilon4 allele is associated with incidental hallucinations and delusions in patients with AD. Neurology. 2004;63:1105-7.

39. Spalletta G, Bernardini S, Bellincampi L, et al. Delusion symptoms are associated with ApoE epsilon4 allelic variant at the early stage of Alzheimer's disease with late onset. Eur J Neurol. 2006;13:176-82.

40. van der Flier WM, Staekenborg S, Pijnenburg YA, et al. Apolipoprotein E genotype influences presence and severity of delusions and aggressive behavior in Alzheimer disease. Dement Geriatr Cogn Disord. 2007;23:42-6.

41. Pritchard AL, Harris J, Pritchard CW, et al. The effect of the apolipoprotein E gene polymorphisms and haplotypes on behavioural and psychological symptoms in probable Alzheimer's disease. J Neurol Neurosurg Psychiatry. 2007;78:123-6.

42. Assal F, Alarcon M, Solomon EC, et al. Association of the serotonin transporter and receptor gene polymorphisms in neuropsychiatric symptoms in Alzheimer disease. Arch Neurol. 2004;61:1249-53.

43. Angelucci F, Bernardini S, Gravina P, et al. Delusion symptoms and response to antipsychotic treatment are associated with the 5-HT2A receptor polymorphism $(102 \mathrm{~T} / \mathrm{C})$ in Alzheimer's disease: a 3-year follow-up longitudinal study. J Alzheimers Dis. 2009;17:203-11.

44. Lam LC, Tang NL, Ma SL, et al. 5-HT2A T102C receptor polymorphism and neuropsychiatric symptoms in Alzheimer's disease. Int J Geriatr Psychiatry. 2004;19:523-6.

45. Holmes C, Arranz MJ, Powell JF, et al. 5-HT2A and 5-HT2C receptor polymorphisms and psychopathology in late onset Alzheimer's disease. Hum Mol Genet. 1998;7:1507-9.

46. Borroni B, Grassi M, Agosti C, et al. Genetic correlates of behavioral endophenotypes in Alzheimer disease: role of COMT, 5-HTTLPR and APOE polymorphisms. Neurobiol Aging. 2006;27:1595-603.

47. Holmes C, Smith H, Ganderton R, et al. Psychosis and aggression in Alzheimer's disease: the effect of dopamine receptor gene variation. J Neurol Neurosurg Psychiatry. 2001;71:777-9.

48. Craig D, Hart DJ, McCool K, et al. The interleukin 1beta gene promoter polymorphism $(-511)$ acts as a risk factor for psychosis in Alzheimer's dementia. Ann Neurol. 2004;56:121-4.

49. - Carson R, Craig D, Hart D, et al. Genetic variation in the alpha 7 nicotinic acetylcholine receptor is associated with delusional symptoms in Alzheimer's disease. Neuromolecular Med. 2008;10:377-84. This was a newer genetic study showing an association of a novel gene in the study of delusions in dementia, but one that has been studied in schizophrenia, demonstrating $a$ potential association between the two.

50. Pollock BG, Mulsant BH, Rosen J, et al. A double-blind comparison of citalopram and risperidone for the treatment of behavioral and psychotic symptoms associated with dementia. Am J Geriatr Psychiatry. 2007;15:942-52. 